\title{
Mechanical performance of bacterial cellulose nanofibre-reinforced epoxy composites
}

\author{
H. Takagi, A. N. Nakagaito \& K. Uchida \\ University of Tokushima, Japan
}

\begin{abstract}
This paper reports the preparation and characterization of a new type of natural fibre nanocomposite composed of bacterial cellulose nanofibres and thermoset epoxy resin. Before combining with epoxy resin, the bacterial cellulose nanofibre was prepared by a freeze-drying process. The effect of nanofibre loading on the mechanical properties of the polymer composites was investigated. The tensile strength of the composites increased with increasing fibre content, and reached the maximum tensile strength value of about $74 \mathrm{MPa}$, almost twice the strength of the plain resin. This strength value was quite low compared with a theoretical estimation. This discrepancy seemed to arise from weak interfacial adhesion.
\end{abstract}

Keywords: bacterial cellulose fibre, composites, epoxy resin, strength, modulus, fracture, debonding.

\section{Introduction}

In recent years, much attention has been focused on plastic waste problems and resource depletion in a global scale [1]. To build a sustainable society, research and development of natural fibre reinforced polymer composites have been carried out on worldwide scale [1]. Some kinds of natural fibre composites exhibit fully-biodegradable characteristics and, therefore, can be disposed off easily; at the same time, there are no additional green house gas emissions even after burning them (namely, they ensure carbon neutrality) [2, 3].

Most of conventional studies on natural fibre composites have been made using macroscopic natural fibre bundles or single natural fibres (e.g. pulp) as reinforcement [4-10]. In the case of macroscopic natural fibres, the latter have often suffered from various kinds of damage introduced during manufacturing, 
resulting in lower than expected mechanical performance with wide scattering. On the contrary, in the case of nanoscale fibres such as cellulose microfibrils, which are extracted from pulp by a high pressure homogenization, it is believed that such fibres have relatively high performance. Therefore the cellulose nanofibres have attracted a great deal of researchers' attention [11-14].

Nakagaito and Yano fabricated high-strength micro-fibrillated cellulose (MFC) fibre-reinforced phenolic composites having a tensile strength of 370 $\mathrm{MPa}$ and a Young's modulus of $19 \mathrm{GPa}$ [11]. Fully biodegradable cellulose nanofibre-reinforced starch-based composites were also developed and it was reported that the mechanical properties of the composites were affected by the processing conditions [12]. Omrani et al. fabricated cellulose nanofibre/epoxy composites having a maximum fibre content of $5 \mathrm{wt} . \%$, however they did not carry out tensile tests, but only dynamic mechanical thermal analysis [13].

The purpose of this paper is to elucidate the applicability of the bacterial cellulose nano-fibre as a reinforcing phase in polymer composites. Bacterial cellulose nanofibre/epoxy composites were fabricated and their mechanical properties were evaluated by tensile tests. In conclusion, it can be seen that the bacterial cellulose nanofibre can be used as the reinforcing phase in a natural fibre composite system.

\section{Experimental methods}

\subsection{Materials}

A bacterial cellulose pellicle was purchased from Fujicco Co. Ltd., Japan (fig. 1). The pellicle in as-received condition was soaked in acetic acid solution. First the pellicle was washed with running water to remove the acid (i.e. neutralize it). The pellicle was cut into $100 \times 45 \times 15 \mathrm{~mm}^{3}$, then frozen at $-15^{\circ} \mathrm{C}$ in a home-use

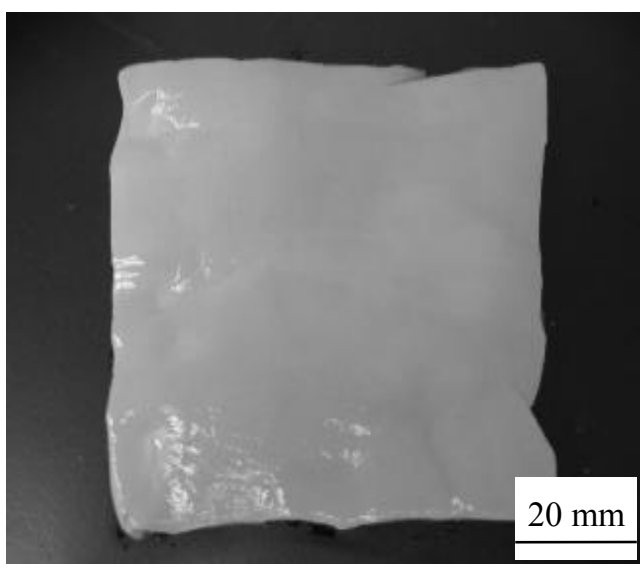

Figure 1: Photograph of bacterial cellulose pellicle. 
freezer. This frozen bacterial cellulose pellicle was freeze-dried for four days using a laboratory freeze-dryer (FDU-1200, Advantec Toyo Kaisha, Ltd., Japan).

Fig. 2 shows a SEM photomicrograph of the freeze-dried bacterial cellulose nanofibre. It can be seen that the bacterial cellulose fibre has nano-scale diameter and web-like complicated microstructure as indicated elsewhere [11, 12]. Additionally, it can be seen that each fibre is slightly curved (namely not straight) and branched at many points, and that its diameter varies from $50 \mathrm{~nm}$ to $200 \mathrm{~nm}$. Low viscosity bisphenol-A epoxy resin (low viscosity epoxy resin \#7062, Refine-Tech. Co., Japan) was used as the matrix polymer.

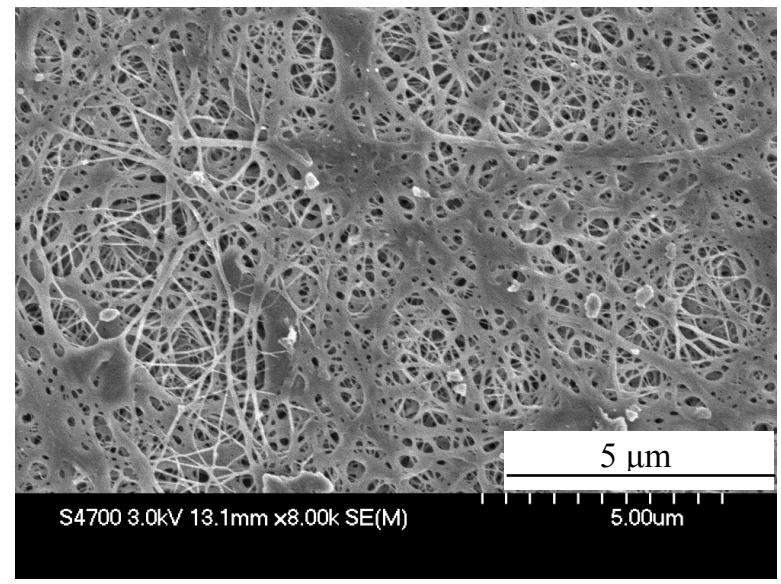

Figure 2: $\quad$ SEM photomicrograph of freeze-dried bacterial cellulose.

\subsection{Sample preparation method}

The freeze-dried pellicle was cut into a rectangular bar of dimensions $100 \times 15 \times 15 \mathrm{~mm}^{3}$ using a wheel-saw cutter. The bar was pressed in a metallic mould at various pressure and room temperature. This pressing process is needed to increase the fibre content of the resultant composite materials. The thickness of the samples ranged from 0.1 to $15 \mathrm{~mm}$. The pressed sheet sample was immersed in epoxy resin in vacuum (about $0.01 \mathrm{MPa}$ ). After complete soaking in epoxy resin, the resin-impregnated sheet was taken out, then placed in another metallic mould, and kept at $80^{\circ} \mathrm{C}$ for $12 \mathrm{~min}$. After complete hardening of the epoxy resin, the sample was post-cured at $80^{\circ} \mathrm{C}$ for 3 hours. Fig. 3 shows the macroscopic photos of the pressed freeze-dried bacterial cellulose sheets with different thicknesses and their composites with epoxy resin. The shape of the composite samples changes after resin-impregnation treatment. The changes in shape are small in the case of the thinner sheet sample (i.e. of $0.1 \mathrm{~mm}$ thickness). Finally the six surfaces of the sheet sample were ground with various sandpapers and then polished with fine alumina powders. 

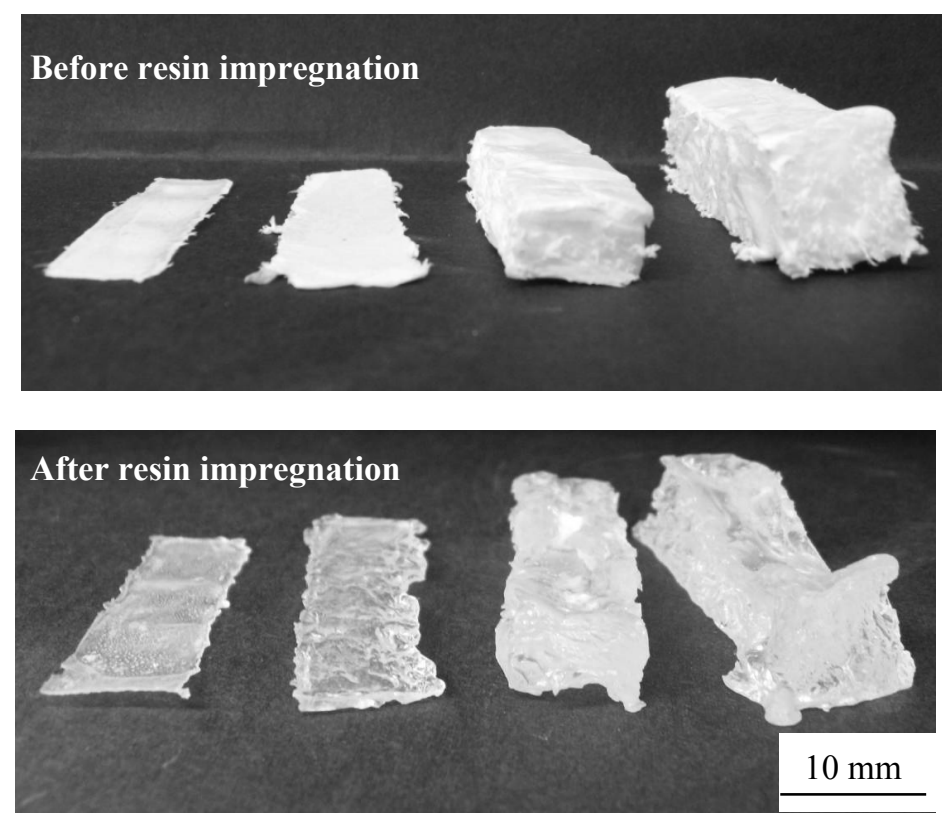

Figure 3: $\quad$ SEM photomicrograph of pressed freeze-dried bacterial cellulose sheets and composites; thickness $=0.1,1.0,7.5$, and $15 \mathrm{~mm}$ from the left).

\subsection{Tensile tests}

Quasi-static static tensile tests were carried out in order to evaluate the mechanical properties and tensile fracture behaviour of the bacterial cellulose composites. The tensile tests were conducted using a universal testing machine (5567, Instron Co., U.S.A) at room temperature. The cross-head speed and gauge length were $1.0 \mathrm{~mm} / \mathrm{min}$ and $30.0 \mathrm{~mm}$, respectively.

\subsection{Surface characterization}

The fracture morphology of the samples after the tensile tests was examined by a field emission-type scanning electron microscope (FE-SEM: S-4700, Hitachi Ltd., Japan). All samples were sputter-coated with platinum-palladium alloy using a sputter coater (E-1020, Hitachi Ltd., Japan) prior to SEM observation.

\section{Experimental results and discussion}

Figure 4 shows typical stress-strain curves for the epoxy composites reinforced with different bacterial cellulose fibre content. The stress-strain curve of plain resin is also shown in the same figure as a reference. It can be seen that mechanical properties such as the tensile strength and Young's modulus increase with increasing fibre content. The fracture strain of the composites ranges from 
0.025 to 0.028 . This strain value is almost similar to the fracture strain of macroscale natural fibres such as hemp fibre and bamboo fibre. Therefore, the fracture of the composites might be governed by the fracture of the bacterial cellulose fibres.

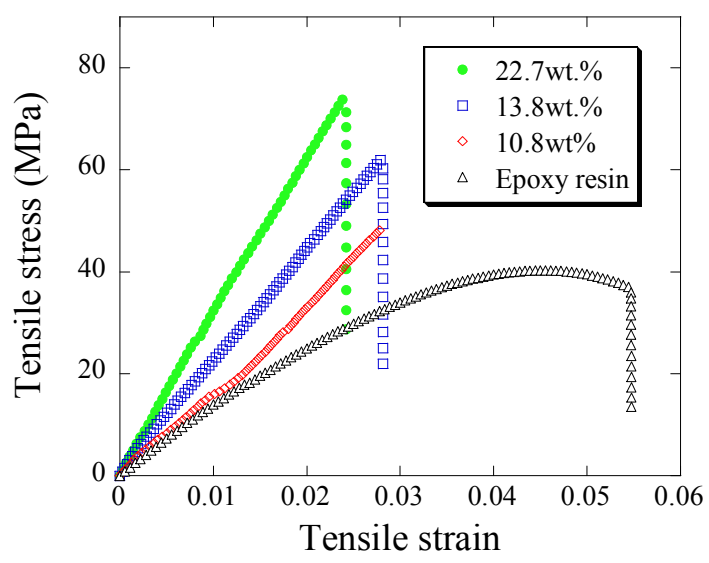

Figure 4: Typical stress-strain curves of the composites.

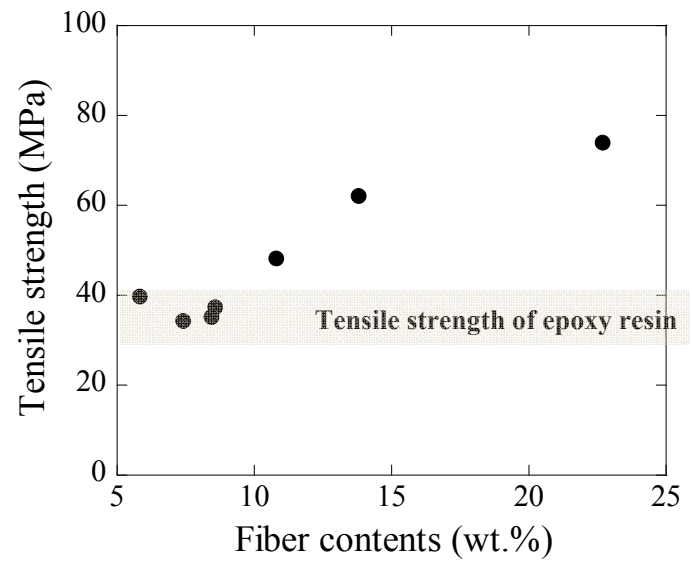

Figure 5: Relationship between tensile strength and fibre content.

The variation of tensile strength of the composites is indicated in fig. 5. The tensile strength increases roughly linearly with fibre content, showing a maximum peak value of $74 \mathrm{MPa}$ at $23 \mathrm{wt} . \%$. This value is almost twice the strength of plain resin. A similar dependence was also reported in cellulose nanofibre/PLA composites, showing the maximum strength increase of about 50wt.\% [14]. It seems therefore that a higher tensile strength might be obtained at higher fibre loading. The tensile strength of MFC was reported at $1700 \mathrm{MPa}$ [15], therefore the present result is quite low compared with the theoretical estimation, which should be higher than $147 \mathrm{MPa}$. 
The tensile fracture behaviour of plain resin and composites are depicted in fig. 6. The fracture surface of epoxy resin is relatively flat and smooth (fig. 6(a)), however that of composites with $11 \mathrm{wt} \%$ fibre is rather complicated and indicates that microscopic fracture occurs in the composites (fig. 6(b)). Figure 6(c) shows an enlarged image of the fracture surface of the same
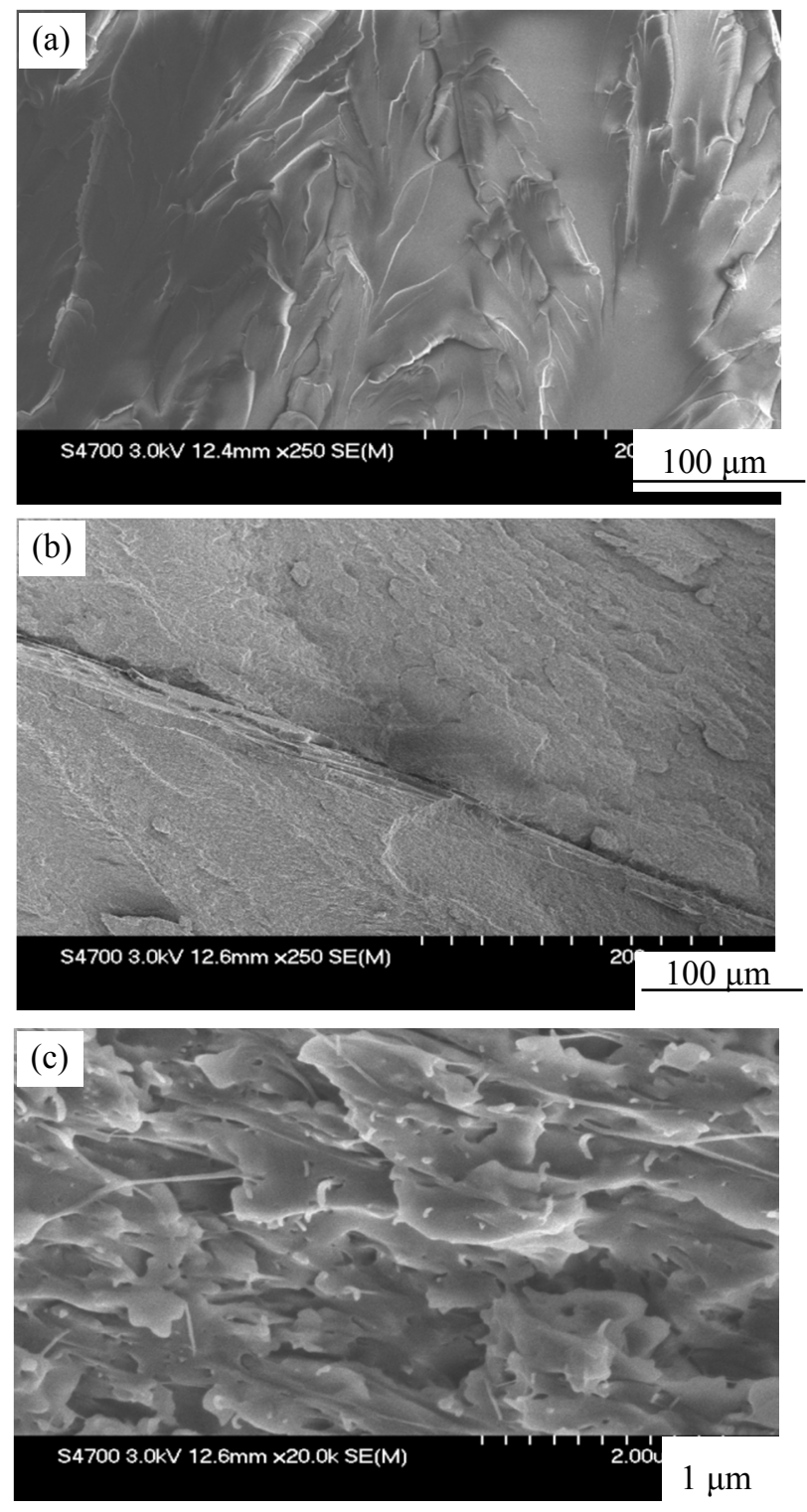

Figure 6: $\quad$ SEM photomicrographs of (a) plain epoxy resin, (b) composites with 11 wt. $\%$ bacterial cellulose fibre, and (c) enlarged image of (b). 
composites, indicating the extensive pull-out of fibres as well as the corresponding holes. This suggests that the interfacial adhesion between cellulose nanofibre and epoxy resin is low in this system, resulting in lower strength compared with the theoretical estimation. Therefore additional surface treatment of the nanofibre is needed to achieve further strengthening.

\section{Conclusions}

In summary, the bacterial cellulose nanofibre reinforced epoxy composites were successfully fabricated using a freeze-dry method. Their tensile strength was almost comparable to that of glass-fibre reinforced plastics. Additional surface treatment of the nanofibre is needed to achieve further strengthening.

\section{References}

[1] Netravali, A.N. \& Chabba, S., Composites get greener. Materials Today, 6(4), pp. 22-29, 2003.

[2] Takagi, H., Kako, S., Kusano, K. \& Ousaka, A., Thermal conductivity of PLA-bamboo fiber composites. Advanced Composite Materials, 16(4), pp. 377-384, 2007.

[3] Wambua, P., Ivens, J. \& Verpoest, I., Natural fibres: can they replace glass in fibre reinforced plastics? Composites Science and Technology, 63(9), pp. 1259-1264, 2003.

[4] Wollerdorfer, M. \& Bader, H., Influence of natural fibres on the mechanical properties of biodegradable polymers. Industrial Crops and Products, 8(2), pp. $105-112,1998$.

[5] Luo, S. \& Netravali, A.N., Interfacial and mechanical properties of environment-friendly "green" composites made from pineapple fibers and poly(hydroxybutyrate-co-valerate) resin. Journal of Materials Science, 34(15), pp. 3709-3719, 1999.

[6] Luo, S. \& Netravali, A.N., Mechanical and thermal properties of environment-friendly green composites made from pineapple leaf fibers and poly(hydroxybutyrate-co-valerate) resin. Polymer Composites, 20(3), pp. 367-378, 1999.

[7] Lodha, P. and Netravali, A.N., Characterization of interfacial and mechanical properties of "green" composites with soy protein isolate and ramie fiber. Journal of Materials Science, 37(17), pp. 3657-3665, 2002.

[8] Mohanty, A.K., Misra, M. \& Hinrichsen, G., Biofibres, biodegradable polymers and biocomposites: An overview. Macromolecular Materials and Engineering, 276/277(1), pp. 1-24, 2000.

[9] Mueller, D.H. \& Krobjilowski, A., New discovery in the properties of composites reinforced with natural fibers. Journal of Industrial Textiles, 33(2), pp. 111-130, 2003.

[10] Takagi, H. \& Ichihara, Y., Effect of fiber length on mechanical properties of "green" composites using a starch-based resin and short bamboo fibers. JSME International Journal, Series A, 47(4), pp. 551-555, 2004. 
94 Natural Filler and Fibre Composites: Development and Characterisation

[11] Nakagaito, A.N. \& Yano, Y., Novel high-strength biocomposites based on microfibrillated cellulose having nano-order-unit web-like network structure. Applied Physics A, 80(1), pp. 155-159, 2005.

[12] Takagi, H. \& Asano, A., Effects of processing conditions on flexural properties of cellulose nanofiber reinforced "green" composites. Composites Part A, 38(4), pp. 685-689, 2008.

[13] Omrani, A., Simon, L.C. \& Rostami, A.A., Influences of cellulose nanofiber on the epoxy network formation. Materials Science and Engineering A, 490(1-2), pp. 131-137, 2008.

[14] Takagi, H., Strength properties of cellulose nanofiber green composites. Key Engineering Materials, 462-463, pp. 576-581, 2011.

[15] Sakurada, I., Nukushina, Y. \& Ito, T., Experimental determination of the elastic modulus of crystalline regions in oriented polymers. Journal of Polymer Science, 57(165), pp. 651-660, 1962. 